\title{
2 \\ Shaping democratic outcomes in the information age
}

\section{Paula Bennett}

During my time as New Zealand's Minister of Local Government, Social Housing and State Services, as well as the Associate Minister of Finance and Tourism, I was interested in how we, the public service-and in that group I include myself-serve the public, the structures we have set up to do so and the data we use to inform our decisions.

Are we really servicing the public for their good? Or have we set up structures in such a way that it suits us as government, but does not reflect the types of lives people are living today, let alone in three or five years time? In my contribution to this volume, I wish to interrogate data analytics and the execution of that within our communities.

In my opinion, data is still largely locked inside servicing silos. We talk about silos frequently, but more important than just looking at it as a structure of the appropriation or the agency is realising that the available data is not being effectively used. Rather than applying it to real people's lives, streets and communities, too often the data is not shared as broadly as I think it should be. I personally feel a huge weight of responsibility. I should. I stand up and try to get re-elected every few years; I am in an incredibly privileged position to be able to instigate change and to work for the better of the people I serve. I genuinely feel that responsibility and I know that other officials do, too. 
Similarly, when it comes to administering the kinds of services that people need, those officials responsible feel the weight of the responsibility to raise the standard to where it needs to be. We know so much about people's lives, but we have yet to work out how to use that knowledge and how to use that information as effectively as possible. In my opinion, what we lack is not data but information on what is happening on the ground, what is happening with people's lives and whether or not government spending is making a difference.

The focus of my chapter is social services, not simply because it is my background but because it represents two-thirds of New Zealand government spending. And if we are not prepared to constantly change the way we deliver services and constantly keep the changing needs of citizens in our minds, this fiscal challenge is only going to increase.

For me, it gets down to what the data actually tells us; the analytics, who to share it with and how. I think the public needs to give us permission to use data and anonymised data that is easy to understand-allowing us to go and say, for example, that there is a certain amount of children in a certain area with certain characteristics.

That is fine, and that can influence our policy decisions and our spending at a national level. But then you are faced with the question of how to use individualised data if you are to target the right kind of children and the right families. I think this is a challenge that we are yet to overcome. To this end, I have spent much of the last four years with my head in data analytics. I am passionate about the execution of this because, with all respect to them, a room full of pointy heads can sit around indefinitely pontificating on what data is relevant, how you merge it and what it actually means. I understand this because I too can get submerged in it and convince myself that it is the way forward.

This is all good and well, but we must then apply that data, I think, to execution: its value rests on what you use it for, how you use it for analysis and how you fast-fail and then build up what needs to be continued and scaled up. One recent example from New Zealand is a white paper on children. Considering we are a successful country full of opportunity, New Zealand suffers a terrible rate of child abuse, as does Australia.

It is to both countries' shame that there are children being seriously hurt and even killed in their own homes. This simply should not be. How do we tackle this? Some predictive modelling we did was instructive. 
Over two years, our data analysts have gone through 200,000 cases, beginning in the mid-1990s, of New Zealand children who have been abused and neglected. Consequently, we can tell you about the 1,000 kids aged between six and nine that are most likely to end up in jail and/ or be seriously hurt or killed. What do we do with this knowledge? It is one thing to have the data and the information; it is quite another to then use it in line with your sense of responsibility. What I worked out was that we needed permission to use it, that it belonged to the New Zealand public. I also realised that all of New Zealand was in on the problem: when I stood up and gave speeches on child abuse, the usual response was that a quarter of the audience would cry and others would tell me that it was the most depressing speech they had ever heard. By contrast, when I would give a speech on welfare, everyone present would have an opinion. This was not true when it came to child abuse; I did not understand how to get that conversation going.

Our response to this problem was the white paper on children. In it we canvassed myriad ideas and we used predictive modelling. The question is, how do we generate interest and engage consultation in a subject that is so taboo; a subject that makes you feel physically ill?

One of the problems we face is that unless you have experience of abuse, it is hard to believe it is happening. And for those who are experiencing it, they are in such chaos and dysfunction that their ability to participate in any kind of process is zero. To combat this, I decided I had to use my political profile; in 2015, I led 32 meetings throughout the country. I purposefully did this in January when news is quiet and the media desperate for stories. This way, I figured, I could generate media and public interest.

We had a caravan travel the length of the country, talking to people and handing out postcards. We harnessed social media to canvass ideas, receiving thousands of submissions from a wide variety of people. In essence, we were asking middle New Zealand whether they were prepared for us to take money off them to spend on these kids; and whether they were prepared to allow us to gather information in order to determine key indicators and risk factors, allowing a more coherent approach to funding. Overwhelmingly, the people we spoke to wanted this to be done. 
As a result of the information we have been gathering, we now know who has lived in a state house and who, generations ago, was under the mandate of Child Protection Services. We know who has been on welfare for generations. We know who was of interest to the police last week, who will be next week, and who has protection orders out against them. Additionally, we now have the infrastructure, in the form of an idealised system that overlays all of our ministries, to pull that data together. This then helps us decide what the key indicators are of where we are seeing failure and what we can do.

Gathering such data means nothing if you are not granted permission to use it. The stakes are high. One need only look to the UK's new child protection service, whose access to information was not handled well, setting them back, in my opinion, perhaps 10 years.

The UK example offers a salutary lesson of why this has to be carefully thought out, and why you need your citizens to understand what it means. In other words, they need a value proposition; you are appealing to a combination of hearts and heads. This is difficult, because we are asking the community to care for a group that they generally do not see and struggle to empathise with, given most New Zealanders live good lives. How do we get citizens to care about this demographic given they have their own worries, albeit less grave? If we genuinely care about others, we have to bring them with us. The public must understand that.

Open and transparent government is crucial. Sometimes I do not think we give the public enough credit for caring about the issues that affect society. In the age of social media, we think that policymakers have to be pithy to engage with the community or they will not be interested. This is false. They will if you engage them in a way that makes them believe they are part of a social contract; that we are all in this together, and that they need to do their bit. It is defeatist to assume that the public are not interested in complex issues, and to assume that you cannot engage them. In my opinion, if you cannot engage them, you have not tried hard enough.

The predictive modelling I have been involved in is a case in point. I would say to these people: 'What would you do if you knew?' 'What do you want me to do?' They had no idea. The general view was: 'Of course you should share information on our most vulnerable children. If you know that there is a history of abuse of the parents themselves, and that you have a custodial parent, of course you should share information'. 
But one day I made the mistake of applying the key indicators to myself. I realised that 17-year-old me, on welfare, living in dismal conditions and living from one crisis to the next probably would have been in that box. Would I have liked my information shared? Would I have liked the prospect of social services were monitoring me and sharing my information with officials from health, education, the police and others? Frankly, it makes me feel squeamish even now.

I make this point to illustrate that it is all good and well when you are considering this information in regards to someone else. It is another matter entirely when it is about you, your family or your kids: suddenly you do not trust the government and they are the ones that hold the information and all of the power. In terms of gaining permission, the moment you do not give that due respect is the moment, in my view, the project fails.

Another thing we did was fundamentally change the whole welfare system by taking the power of politics out of the decisions of welfare. To do this, I introduced a multi-category appropriation (MCA), because too often politicians assume that because the public cares about youth, more money should be spent on youth-even though that might not be what the valuation and the data are telling you to be the most risky demographic.

In actual fact, what most of the data tells you is that it is those with lowlevel mental illness and the 50,000 people with back pain and obesity issues in our welfare system that need not be there if we had a different health response to them earlier. In this way, data can direct your spending. After introducing the MCA, I was told I was the first minister ever to give themselves less power. But with the use of data we have access to now, such a move was necessary.

And not only did we get voted back in but I ended up being the longestserving welfare minister at that time. We did that by bringing the public with us while we drove a truck through fundamental system changes.

I would like to now move on to the issue of welfare valuation. With the help of Taylor Fry, an Australian firm, we applied an actuarial approach to everyone on New Zealand welfare. Why? Because having once been a single mother on welfare myself before finally landing a breakout job, I understand that what women in that position lack is confidence. They do not believe in themselves; they need to be asked what they want to do, and they need more backing when it comes to skills like writing CVs. 
If we do this, spending a little more money at an early stage, we will get them off welfare. It's not the case that these women do not want to be off welfare-they just don't know how to get off it. Most of them have consistently been told they are rubbish; government has a responsibility to intervene early and set expectations higher for these women. All we need is a little more money at an earlier stage.

When I took this proposal to Treasury they were less than impressed, as was the Minister of Finance. I was told that we have increased spending over a sustained period of time only to see an increase in the number of welfare recipients. We are seeing, I was told, intergenerational welfare dependence at its highest, with more babies being born to women on welfare than ever before. If it was all about the money, they said, things would have changed by now. I realised I had to prove them wrong, which is why we did the valuation. Because ultimately what it did was give the statistics a level of openness and transparency that we had never seen before.

Thanks to this approach, we could see both where we were failing and where we were spending. It was easy. Armed with this information, we took all those people that were currently on welfare and figured out the characteristics of what we knew about them as a cohort. We then measured that over their lifetime and came up with a big number. The big number mattered because it got attention, but what really mattered was the micro information underneath the macro statistics.

We could literally look at the micro as far as cohorts, then break that up however we wanted, whether by region or by putting it in different characteristics, right down to the individual. We reached a point whereby, hopefully, any individual who walks through our door will know, at the tap of a keyboard, that their parents, for example, were on welfare for 50 years, that they have lived in public housing their entire life and that their risk factor for staying on welfare for a very long time is extremely high-making it worth us spending $\$ 30,000$ in the next eight months to see if we can turn that around.

The first valuation of the total cost before the changes reported a NZ $\$ 78$ billion liability; the next, after the changes, reduced that projection to NZ\$69 billion. We saw real results as to what we were doing and whether it was working. This approach allows us to hone in on revealing details: 3.8 per cent of the drop between the two valuations, for example, was due to welfare reforms. That is the kind of detail we 
can get into. Granted, there are different factors to consider, such as the Consumer Price Index, but we can establish with confidence that 3.8 per cent of that $\$ 9$ billion difference was due to welfare reforms. It is working. We are expecting more reductions, and we are on track for it.

I wish to now outline what we did with youth services in regards to data. According to conventional wisdom, the earlier you go on welfare the longer you are going to stay there and the higher the cost to the state. You think? But then we could literally break it down to where. To try to do this, then deputy prime minister Bill English thought, why don't we make it simple? We don't want them going on welfare. That is our outcome. Once we declared that to be our outcome, we decided that no longer could the government put kids on welfare. We just said no. Instead, we contracted with community youth organisations to set up a whole new system for kids who are not engaged in education, employment or training (NEET). We assigned our NEET kids a risk factor from low to very high, and we then put a monetary amount next to that risk factor because we did not want those youth services all skewing to the easier kids; we wanted to pay more for the more difficult cases.

We then told both the youth service and the kids themselves what outcomes we expected. And we rewarded the kids for the kind of behaviours we wanted. For example, once they have done six months in education, we give them an extra $\$ 10$ a week, as we do once they have completed a budgeting course for six months. By this stage, we no longer give them cash, but instead pay their rent directly and put a small amount-no more than $\$ 50$ - onto a plastic card that they can spend. As for the youth services themselves, we pay them both an administration fee and a series of payments based on the milestones they achieve over a significant period of time. In this way, it is not just about the kids not going on welfare; it is about us making sure we reward positive behaviour to keep them off it.

This has now been running since 2012. In that time, we have seen a 21 per cent reduction in the number of young people going on welfare at the age of 19, a staggering drop. And yet, there are a few things we have not done that we should have, which is always the challenge of learning. While we may have collected really good data on who, what we did not do, but are now doing, is collect information on what the more successful organisations are doing. That said, in the space of three years we have managed to accomplish the lowest number of New Zealand's single parents on welfare since 1988 . 
We achieved that through data analytics: working out exactly who we are going to work with. We then individualised the data to avoid having to anonymise it, because we were doing it within the Ministry of Social Development's Work and Income. Looking at Work and Income, we had 300 women, all with similar characteristics; we decided to contract out 100, do intensive case management with 100 more and do nothing at all with the remaining 100 . We then analysed the results at the 12-week mark, because that is how long it takes to get someone off welfare and into meaningful work. We could then evaluate the success or not and scale up what worked and stop what did not. It is that easy.

I wish to now turn to New Zealand's Better Public Services (BPS). ${ }^{1}$ We have 10 of them, and they have changed the face of how government works. Although they encompass more than just social services, as State Services Minister I am responsible for all 10. As mentioned earlier, through this system we now have 38,000 fewer people on benefit. That equates to 42,000 children no longer growing up in a welfare-dependent home.

Collaboration is a challenge. The only way we will get more people off welfare, intervene in early childhood development and reduce crime is by engaging in cross-agency work. To that end, we are working on making it part of a chief executive's performance appraisal that they can demonstrably show that they have worked towards a BPS target that is not their responsibility.

Knowledge sharing is vital, and ongoing. One of the collaborative projects we tried to set up were the children's teams, an intensive group of professionals who are working with our most vulnerable. Interestingly, they shared less information when we put them together formally. They had been sharing information beforehand-with police, with social workers, with health professionals and with others-but once we put a formal structure around them, they questioned whether the sharing they had been doing was entirely above board. They actually stopped it, which is why execution is so important.

To that end, we now have an Approved Information Sharing Agreement in New Zealand, which we use often. Initially, this was an informationsharing agreement between government departments, but we have recently

1 Note that New Zealand's Better Public Services targets were refreshed on 3 May 2017: beehive. govt.nz/release/new-better-public-services-targets. 
extended it to non-government organisations, sharing information internally. Should the next step be permission to share information from the people in question? I don't know. Should the parents of high-risk kids know that you see them as such and that you are going to spend more money on them? These are the sorts of things that we need to be debating: when it comes to the ethics of information sharing, we are better than we were, but we are far from perfect.

But how do we get departments to buy in, not just with their words but with their actions? To take that welfare valuation and welfare investment approach and build it across the whole social sector? This is the next challenge. And we have now worked out who we will focus on. We are going for that most vulnerable 15 per cent of the population. With the help of integrated data—which is where the data all sits—we have agreed on our key indicators.

These are for children: we are looking at the ages $0-5$ or $12-24$, and we are looking at the long-term benefit receipt. We consider whether an individual child has been at the attention of Child Protection Services, and find out whether they have a custodial parent and whether the child's mother has no education qualifications. Having two of those attributes is true for around 5 or 6 per cent of the population. To give you an indication, this means in a small city of New Zealand, where there are an average of 19,500 people aged $0-17,477$ of them have had a custodial parent at some stage, been at the attention of Child Protection Services and spent more than three-quarters of their life on welfare.

I have a few bottom lines. Basically, anything we do has to be positive for me to consider it a bottom line. The analytical techniques I have outlined in this chapter so far are one thing, but unless we fundamentally change how we work-what I call adaptive contracting - it means nothing to the children in question. In this way, if we do not spend as much time on execution as we are on the data analytics, we are doing a disservice to those 477 children.

Without help, these children have a dreadful future ahead of them. Essentially, unless we are succeeding at the execution stage, we will not be providing them with the kind of service they need. For me, execution has to be place-based. Why then has it not worked to the extent that it needs to? Quite simply, it is because politicians and senior bureaucrats tend to want to keep control. We are scared of failure, because we do not know 
how to manage risk and, when it comes down to it, we have not handed over the mandate and have not handed over the real money. I hope data analytics can be used to overcome our fears of mandate, accountability and risk with public money. We can genuinely use it.

Returning to those 477 children, people who understand data analytics recognise that if you know that there are a certain number of children in a certain place with certain characteristics, they display shared likely outcomes. Data analytics provides you with the indicators to measure success.

We need to stop telling these children what to do, and instead tell them what we want from them and clearly articulate how their success-or not-will be measured. Then give them all the flexibility in the world. By this, I mean looking at joint venture boards with real mandates and real money behind them, with a percentage of budgets that then measure success so they know exactly which children need help. Can we give them individual children's names? We are yet to work that one out.

To conclude, I would like to share a point that illustrates how serious we are about transparency in our next stage of work. One per cent of New Zealand five-year-olds are in families supported by benefits. If we look at an average group of 10 of those five-year-olds, they are high risk. Seven will not achieve education qualifications, four will go on to be on longterm welfare, and one-quarter will go to prison. In financial terms, each child in this group will cost taxpayers a minimum of NZ\$320,000 over their lives, with some costing NZ\$1 million. These figures are certainly attention-grabbing. Now the challenge is to execute a response. 
This text is taken from Opening Government: Transparency and Engagement in the Information Age, edited by John Wanna and Sam Vincent, published 2018 by ANU Press, The Australian National University, Canberra, Australia.

doi.org/10.22459/OG.04.2018.02 